\title{
Why some religious individuals are not emotionally smart? The explanatory role of spirituality
}

\author{
Hui Wen Ng${ }^{1}$, Kususanto Prihadi ${ }^{2}$ \\ ${ }^{1}$ Department of Psychology, HELP University, Malaysia \\ ${ }^{2}$ Center of Cyberpsychology and Games, Dept. of Psychology, HELP University, Malaysia
}

\begin{tabular}{l} 
Article Info \\
\hline Article history: \\
Received Dec 26, 2019 \\
Revised Feb 2, 2020 \\
Accepted Feb 22, 2020 \\
\hline Keywords: \\
Emotional intelligence \\
Internal religious orientation \\
Religiosity \\
Spirituality
\end{tabular}

Article Info

Article history:

Received Dec 26, 2019

Revised Feb 2, 2020

Accepted Feb 22, 2020

Internal religious orientation

Spirituality

\begin{abstract}
In two studies, we intend to investigate whether spirituality can explain the relationship between intrinsic religious orientation (IRO) and emotional intelligence (EI). Seventy-three worshipping houses-going adults, aged 1856 , had participated in the study. Data was collected by employing Intrinsic Scale of Religious Orientation Scale, Spirituality Assessment Scale, and the Schutte Self-Report Emotional Intelligence Test. Our first study discovered that IRO is not a significant predictor of EI. Nevertheless, Bootstrap analysis with 5000 samples and $95 \%$ interval confidence indicated that spirituality fully mediated the link between intrinsic religious orientation and emotional intelligence in our second study. In other words, without high level of spirituality one's religious orientation does not significantly predict their emotional intelligence. Limitation and suggestion are discussed at the end of the paper.
\end{abstract}

This is an open access article under the CC BY-SA license.

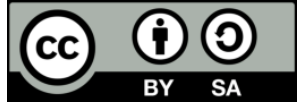

\section{Corresponding Author:}

Kususanto Ditto Prihadi,

Center of Cyberpsychology and Games

Department of Psychology,

Higher Education Learning Philosophy (HELP) University,

No. 15, Sri Semantan 1 Street, Off, Semantan Street, Bukit Damansara, 50490 Kuala Lumpur, Malaysia.

Email: prihadi.k@help.edu.my

\section{INTRODUCTION}

Emotional Intelligence (EI) is a term first used by Salovey and Mayer in 1990 [1-3]. In general, EI is conceptually and operationally defined in two distinct approaches: ability EI and trait EI [4]. Ability EI refers to the ability to perceive, understand and manage one's emotions and the emotions of others, as well as the ability to utilize emotion in enhancing one's thought and behaviour [5]. It is also suggested that emotionally intelligent individuals are competent in four domains namely self-awareness, self-management, social awareness as well as social skills; they can use them effectively in different situations [6]. Seen as a form of cognitive-emotional ability, it is assessed through tests that measure one's maximum performance [7]. On the other hand, trait EI is conceptualized as a cluster of self-perceived traits, such as empathy and self-esteem, that is emotion-related, "located at lower levels of personality hierarchies" [8]. It is based on one's subjective perception of one's emotional ability [9]. In contrast with ability EI, trait EI is measured through self-reported or personality-like scales [4].

Drawing the attention of psychologists, EI is said to be a more important determiner of success than the conventional intelligence [10]. According to past research, EI has found to be positively correlated to job performance [11,12], academic performance [13,14] and effective leadership [15]. Furthermore, people with higher EI were reported to be more likely to interact better in social environment and develop higher social relationship quality [16]. Their ability to understand and utilize emotion helps them in their organization, 
such as workplaces and schools, where they can help in creating a positive social environment, as well as encouraging others positively [17]. Most importantly, EI is positively correlated to life satisfaction [18], self-esteem [19], and mental health [20]. The few aforementioned studies indicated the significance of EI development in educational institutions, families, and general societies. In order to obtain further knowledge in developing EI, it is also significant to know the factors of EI; through this current study, we investigate two factors that have been reported to have positive relationship to EI, namely religiosity and spirituality.

Emotion has been reported to be closely related to religiosity and spirituality [21]; the link can be justified because in among its believers, religion is considered as the centre of life that contributes a significant amount of influences thoughts and attitudes on daily life experiences, as well as their emotional experiences [22]. In line with that, religiosity and spirituality had been reported to lead to greater subjective happiness and increasing one's subjective well-being [23]. Besides that, it was found that spirituality positively predicted resilience and positive emotions [24]. In line with that, it was also reported shown that positive emotions that are self-transcendent such as love and gratitude mediated the relationship between religiosity/spirituality and well-being [25].

In relation to EI, it was suggested that religious teachings and close emotional experience with the Divine Being might affect our emotional manifestation and regulation [26]. Such religious teachings and practices often serve as a means for the believers to buffer against different life situations [21]. Through involvement in religion, religious individuals tend to be better at coping with life situation by putting their trust in a higher power as well as searching for spiritual and social support from people or leaders of the same religion [27]. They also learned to see negative circumstances in a positive light by attaching meaning to their daily encounters [28]. In other words, religious individual will have the tendency to attribute negative life events as a lesson or challenge from the Divine Being that would eventually help them in becoming a better person [29]. In a study done by Vishkin et al. [22], it was found that religious people tend to engage in cognitive reappraisal more frequently and it was found to be effective. Additionally, the researchers found that the frequent and effective application of such emotion-regulating strategy helps in contributing to the greater experiences of positive affect [30]. With that, the present study intends to investigate the predictive relationship between religiosity, spirituality and emotional intelligence.

Since 1990's, spirituality has slowly emerged as a variable distinct from religiosity [31]. While it was being used interchangeably with religiosity, disctinction between spirituality and religiosity has gained its own attention and interest of various studies. In general, religion refers to institutionalized belief systems which includes practices of rituals and reading of specific sacred transcriptions in relation to a Divine Being [29]. On the other hand, spirituality is viewed as the personal search of an existential meaning or the ultimate purpose of life and/or a personal feeling of close connection with a Higher Power [32]. According to Howden [33], spirituality is shown through four dimensions, namely (a) unifying inter-connectedness with self, others, universe and/or the Ultimate Being, (b) searching for purpose and meaning in life, (c) finding empowerment, or feeling capable and at ease through innerness or inner resources when going through difficulties in life, and (d) transcendence, the ability to reach for experiences that are beyond the usual and the ability for self-healing. Spiritual people tend to develop close and meaningful connection with the Higher Power, and they tend to attribute life encounters to the Higher Power in search for life's meaning [34]. Such pursuit of meaning or Deity is not necessarily bounded by religious practice or rituals, or a religious organization [35]. In other words, religion often includes spirituality whereas spirituality can be sought through or without involving in religion [36]. This can be demonstrated clearly by people who claims to be spiritual but at the same time did not identify themselves as religious [37, 38].

In conjunction with the definition of religious orientation explained by Allport and Ross [39], spirituality can be differentiated better from religiosity; religious orientation is the degree one lives out his or her religion. People with extrinsic religious orientation (ERO) uses religion as a way to obtain personal goals, such as social support, financial support, political support, and other non-spiritual objectives; individuals with intrinsic religious orientation (IRO), however, place less focus on the needs of themselves, live with the religion and embrace the teachings completely. They are motivated to live and understand life through their religious belief [40]. Though their own needs such as money and emotions might influence their lives, they strive to make their own goal in concordance with their religious teachings and beliefs [39]. That is to say, engagement in religious organization, rituals, or practices not necessary guarantee spirituality as some religious individuals may not be religious for the sake of religion, but for some self-centred reasons [35].

It was suggested that relationship between religiosity and EI tend to be unstable; Van Dyke and Elias [41] reported negative correlation between religiosity and self-reported EI, whereas, Łowicki and Zajenkowski [42] suggested that religiosity was positively correlated with ability EI but not trait EI. However, by applying the religious orientation concept of Allport and Ross [39], there seems to be a consistent finding on the relationship between religious orientation and EI. According to the past research, IRO shows a significant positive correlation with self-reported EI and negative correlational relationship 
between ERO with self-reported EI [43, 44]. In other words, people who utilize religion for their personal non-spiritual benefits tend to be emotionally less intelligent. This relationship could be due to the increase of engagement in religious practices and ministry by people with higher IRO [43]. Having exposed to religious practices and societies which often involved service of compassion and care, they gradually become more aware of one's emotions and of others and are able to regulate emotions more efficiently [4, 44]. Additionally, it was also suggested that people with higher IRO are better at perceiving and understanding emotions as they are often spiritually more matured [45]. On top of that, Łowicki and Zajenkowski [42] used the ability test of EI for his study and found the negative correlation between ERO and both ability and trait EI. In contrast with the past studies, there is no significant relationship between IRO and EI [42]. As suggested, the inconsistency might be explained by the differences among the culture of different denominations of religions, and even inter-regligions, such as different denominations of Judaism, Islam, and Christianity [42]. The insignificant link between IRO and EI can be further explained in the case of Christianity denomination differences, where the Catholics, whose denomination usually value religiosity through religious practices, rituals and traditions, tend to report a lower IRO as compared to Protestants who usually seek to understand religion at a more independent approach [46]. Thus, self-reporting religiosity can be depending on how each participant interpret religiosity, either external or internal, as well as either ritualbased (e.g. how many times in a month they visited worshipping houses) or faith-based (How true they believe in the divine power).

On the other hand, spirituality has reported to be correlated with EI. Geula [47] reported that the emotional connection with a divine entity is related to one's spiritual well-being. Moreover, such emotional connection could help one to go through negative events as the practice of spirituality allows them to attach meaning and hope to different encounters, promoting positive state of mind [48]. Besides that, de Souza [38] also suggested that spirituality is closely linked to empathy. It was said that spirituality, defined as having a deep connection with self and others, helps one to be able to identify and share the feelings of others [49, 38]. Moreover, Tang, Hölzel, \& Posner [50] reported that brain regions that regulate emotion changed structurally and functionally through spiritual practices like mindfulness meditation. Through meditation, empathy can be cultivated as it helps one in understanding the emotions of others [51]. Given that empathy was known as one of the important features of EI, it was suggested that spirituality is associated with EI [52, 53, 10]. Findings of Lee Flores, Green, Duncan and Carmody-Bubb [54], and Miguel-Rojas, Vílchez-Quevedo and Reyes-Bossio [55], suggested that daily spiritual experiences and spirituality has positive correlation with trait EI. Further analysis showed that selfconsciousness, one of the spiritual dimensions, was significantly and positively associated with emotional regulation and understanding aspect of EI [55]; spiritual practices help one to be aware of one's own emotional state, which in turn helps him or her to understand and regulate emotions better.

Past studies on EI related to spirituality and IRO suggested the necessity of investigating both spirituality and religiosity as a model predicting EI. Not only that spirituality has gradually become a construct differ from religiosity, past research showed that spirituality might be replacing religiosity as more people began to identify themselves as spiritual than religious $[38,56,57]$. Given that, it is important to study how the interaction of both variables influence EI to improve the theoretical understanding of the relationship between IRO and EI, as well as to widen the knowledge regarding the possible means of developing EI. The current research, therefore, aims to investigate whether IRO and spirituality would significantly predict EI. In the study, questionnaires regarding IRO, spirituality and EI would be given to the participants to complete. In conjunction with the past studies, it was hypothesized that intrinsic religious orientation and spirituality would significantly predict emotional intelligence.

\section{RESEARCH METHOD}

\subsection{Participants}

Result of $\mathrm{G}^{*}$ power analysis suggested that at least 68 participants were needed for this study to achieve effect size $=.15, \alpha=.05$, and Power $=.80$. Purposive sampling method was employed to recruit 73 participants were recruited from as they were required to be worshipping house-going adults, (47 females and 26 males), age ranged between 18 to 56 years old $(M=27.42, S D=10.28)$. The actual number of participants were 89; however, in order to ensure the quality of the data, 16 participants were excluded due to the demographic issues and conflict of interests. A google link along with the description and requirements of the study was posted on social media platforms: Facebook and WhatsApp. After reading the post, participants voluntarily participate in the study as they meet the requirements stated by clicking into the google link and answering the questionnaires in the link. 


\subsection{Materials and procedure}

As operationally defined, IRO is known by the total score obtained from the Intrinsic Scale of Religious Orientation Scale (ROS) on a 9-points Likert scale, where the higher the score indicates higher IRO [39, 58]. Spirituality is measured through the total score obtained from the Spirituality Assessment Scale [33] on a 6-points Likert scale, where the higher the total score indicates higher spirituality; whereas EI is operationally defined as the total score obtained from the Schutte Self-Report Emotional Intelligence Test (SREIT) by Schutte et al. [59] on a 5-point Likert scale, where the higher the score indicates higher EI.

A google link was extracted after the google form including the informed consent form, demographic questionnaire, Intrinsic Scale of ROS, SAS and SREIT was constructed. It was then posted along with a brief description of the study as well as the requirements to participate in the study on two social media platforms, namely Facebook and WhatsApp, after gaining approval of the admin if it was a social media group page. Participants interested in joining the study would then click on the link posted. They were first presented with the informed consent form which inform them on the purpose and requirements of the study, and also their rights as a participant when they clicked on the link. As they met the requirement and agreed to take part in the study, they were required to check on the "I Agree" box to continue with the study. After that, participants were required to fill in the demographic questionnaire, Intrinsic Scale of ROS, SAS, and SREIT. The whole process should be no longer than 45 minutes.

\section{RESULTS AND DISCUSSION}

\subsection{Study one}

The aim of this study is to investigate the predictive relationship of IRO, spirituality and EI; thus, the data obtained from the participants were further examined using Forced Entry Multiple Linear Regression. Participants' scores on IRO was obtained through adding the scores of each item on the IRO scale, where the higher the score indicate higher total IRO. Likewise, the sum of each item of the SAS scale was also calculated as a measurement of participants' spirituality score, where the higher the total score indicate higher spirituality. Participants' score on self-reported EI was then obtained through totalling the scores of each item on the SREIT scale after reversing the score for item 5, 28 and 33. The higher the total score on the SREIT scale indicates better emotional intelligence. The data are presented in Table 1 and Table 2.

Table 1. Mean scores for spirituality, intrinsic religious orientation and emotional intelligence

\begin{tabular}{lccc}
\hline & $\mathrm{M}$ & $\mathrm{SD}$ & $\mathrm{N}$ \\
\hline Emotional Intelligence & 125.29 & 10.42 & 73 \\
Intrinsic Religious Orientation & 62.34 & 12.24 & 73 \\
Spirituality & 128.16 & 19.67 & 73 \\
\hline
\end{tabular}

Table 2. Summary of forced entry regression analysis for intrinsic religious orientation and spirituality

\begin{tabular}{|c|c|c|c|c|}
\hline & $\mathrm{b}$ & $\beta$ & $\mathrm{t}$ & $\mathrm{p}$ \\
\hline Constant & 76.61 & & 13.85 & .000 \\
\hline Intrinsic Religious Orientation & -.13 & -.15 & -1.55 & .126 \\
\hline Spirituality & .44 & .83 & 8.69 & .000 \\
\hline
\end{tabular}

As shown in Table 2, the overall model of IRO $(M=62.34, S D=12.24)$ and spirituality $(M=$ $128.16, S D=19.67)$ significantly predicted $57.2 \%$ of the variance in $\mathrm{EI}(M=125.29, S D=10.42), R^{2}=.57$, $F(2,70)=46.84, p<.001$.

However, looking further into the analysis, IRO was not a significant predictor of EI when controlling for spirituality, $\beta=-.15, t(70)=-1.55, p=.126$. Spirituality was a significant predictor of EI when controlling for IRO, $\beta=.83, t(70)=8.69, p<.001$. The regression equation in this study is Emotional Intelligence $=76.61+(-.13 \times$ IRO $)+(.44 \times$ Spirituality $)$. Given that IRO was found to be insignificant predictor of EI when controlling for spirituality, the relationship of IRO and spirituality in addition to the initial study. The analysis of standard residuals showed that there were two outliers as the standard residual values did not stay between negative and positive three, Std. Residual Min = -3.08, Std. Residual $\operatorname{Max}=2.14$. Therefore, the research decided to remove the outliers, which were participant 7 and 31 , to continue the analysis. Table 3 , Table 4 , and Table 5 showed the results before and after the removal of outliers. 
Table 3. Residuals statistics ${ }^{\text {a }}$ before the removal of outliers

\begin{tabular}{lccccc}
\hline & Minimum & Maximum & Mean & Std. Deviation & $\mathrm{N}$ \\
\hline Predicted Value & 83.28 & 144.56 & 128.16 & 11.366 & 73 \\
Residual & -49.775 & 34.583 & .000 & 16.049 & 73 \\
Std. Predicted Value & -3.949 & 1.442 & .000 & 1.000 & 73 \\
Std. Residual & -3.080 & 2.140 & .000 & .993 & 73 \\
\hline
\end{tabular}

${ }^{\mathrm{a}}$ Dependent Variable: Spirituality

Table 4. Residuals statistics ${ }^{\mathrm{a}}$ after the removal of outliers

\begin{tabular}{lccccc}
\hline & Minimum & Maximum & Mean & Std. Deviation & N \\
\hline Predicted Value & 106.34 & 144.30 & 129.65 & 9.462 & 71 \\
Residual & -38.108 & 34.051 & .000 & 15.048 & 71 \\
Std. Predicted Value & -2.463 & 1.549 & .000 & 1.000 & 71 \\
Std. Residual & -2.514 & 2.247 & .000 & .993 & 71 \\
\hline
\end{tabular}

${ }^{a}$ Dependent Variable: Spirituality

Table 5. Mean scores for spirituality and intrinsic religious orientation

\begin{tabular}{lccc}
\hline & $\mathrm{M}$ & $\mathrm{SD}$ & $\mathrm{N}$ \\
\hline Intrinsic Religious Orientation & 63.01 & 10.97 & 71 \\
Spirituality & 129.65 & 17.78 & 71 \\
\hline
\end{tabular}

After removing the outliers, the analysis of standard residuals showed increased in minimum and maximum values of standard residual, Std. Residual Min $=-2.51$, Std. Residual Max $=2.25$. By visually inspecting the scatterplot of IRO against spirituality (Figure 1), the assumption of linearity between IRO and spirituality was met.

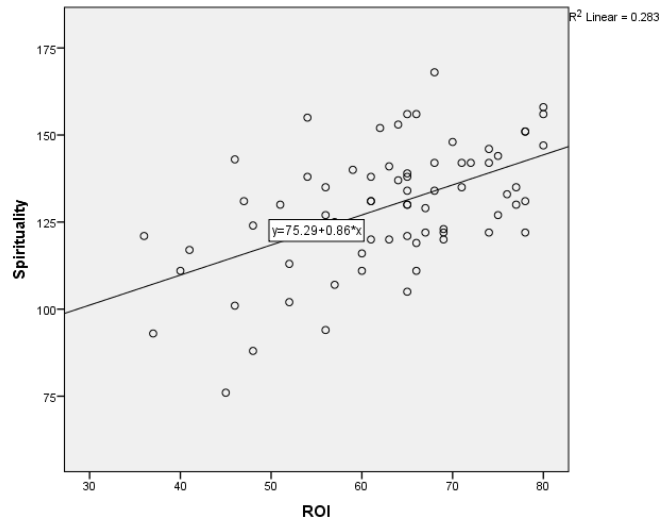

Figure 1. Assumption of linearity for internal religious orientation predicting spirituality

Furthermore, assumption of no multicollinearity was tested, and the results are depicted in Table 6 for correlations and Table 7 for coefficient.

Table 6. Correlations

\begin{tabular}{cccc}
\hline \multicolumn{3}{c}{ Spirituality } & IRO \\
\hline Pearson CorrelationSpirituality & 1.000 & .532 \\
& IRO & .532 & 1.000 \\
Sig. (1-tailed) & Spirituality &. & .000 \\
& IRO & .000 &. \\
N & Spirituality & 71 & 71 \\
& IRO & 71 & 71 \\
\hline
\end{tabular}

Table 7. Coefficients ${ }^{\mathrm{a}}$

\begin{tabular}{|c|c|c|}
\hline & \multicolumn{2}{|c|}{ Collinearity Statistics } \\
\hline $\begin{array}{c}\text { Model } \\
\text { 1(Constant) }\end{array}$ & Tolerance & VIF \\
\hline IRO & 1.000 & 1.000 \\
\hline
\end{tabular}


Given that the tolerance value is more than 0.2 and the VIF value is lesser than 10 , the assumption of no multicollinearity was met, Tolerance $=1.00$ and VIF $=1.00$. 1 . The final result of the regression analysis is summarized in Table 8

Table 8. Summary of simple linear regression analysis for intrinsic religious orientation predicting

\begin{tabular}{lcccc}
\multicolumn{5}{c}{ spirituality $(\mathrm{N}=71)$} \\
\hline b & $\beta$ & $\mathrm{t}$ & $\mathrm{p}$ \\
\hline Constant & 75.29 & & 7.13 & .000 \\
Intrinsic Religious Orientation; & .86 & .53 & 5.22 & .000 \\
\hline$b=$ unstandardized beta coefficient; $\beta=$ standardized beta coefficient; $\mathrm{R}=.53 ; R^{2}=.28 ;$ & $F(1,69)=27.28, p<.001$
\end{tabular}

Table 8 showed that the model of IRO $(M=63.01, S D=10.97)$ significantly predicted spirituality $(M=129.65, S D=17.78), F(1,69)=27.28, p<.001$. IRO explained $28.3 \%$ of the variance of spirituality, $R^{2}$ $=.28$. IRO was a significant predictor of spirituality, $\beta=.53, t(69)=5.22, p<.001$. As shown in the result, the regression equation is Spirituality $=75.29+(.86 \times$ IRO $)$.

\subsection{Conclusion of study one}

Findings of our first study indicated that when counted individually, spirituality significantly predicts EI, while IRO does not. However, as mentioned in Table 8, spirituality is significantly predicted by IRO. Further explanation is required at this point, because while spirituality predicts EI, one will not be spiritual without IRO; yet IRO does not significantly predict EI. Study two was conducted in order to investigate how the the interaction of IRO and spirituality works in predicting EI.

\subsection{Study two}

Using the same dataset, total effect of IRO and spirituality against EI is being tested. A mediation model was chosen because there was evidence that IRO significantly predicts EI in the context of this study (Table 8); which means that one might not be spiritual without having religious orientation internally. A bootstrap analysis with 5000 samples and $95 \%$ interval confidence was chosen due to the robustness of the analysis method. PROCESS Macro within SPSS was utilized in order to conduct the analysis, and Table 9 summarized the results.

Table 9. Multiple regression among the variables

\begin{tabular}{lcccccc}
\hline & $\mathrm{R}^{2}$ & $\mathrm{t}$ & $\beta$ & $\mathrm{P}$ & LLCI & ULCI \\
\hline Total: IRO as a model $\rightarrow$ EI & .11 & 2.97 & .28 & .004 & .093 & .047 \\
Direct: IRO $\rightarrow$ EI & & -1.55 & -.13 & .13 & -.29 & .04 \\
& & \multicolumn{2}{c}{ Boot SE } & Boot LLCI & Boot ULCI \\
Indirect: IRO $\rightarrow$ Spirituality $\rightarrow$ EI & & .41 & .093 & .24 & .60 \\
\hline
\end{tabular}

Table 9 depicted that the total effect of IRO as a model (together with spirituality) on EI was significant, and one increment of the model IRO predicts the 0.28 points of EI. However, when spirituality is taken out from the equation, IRO lost its significance in predicting EI. At the last row of the Table 9, it was shown that spirituality can explain the link between IRO and EI. Thus, it can be concluded that religiosity is not a significant predictor of EI without spirituality; in other words, religious or not, people can still be emotionally intelligence when they develop a sense of spirituality. The second conclusion to be drawn is that IRO can only predict EI when mediated by spirituality; in other words, people who are religious without actually being spiritual will not likely to have their EI affected by their religiosity.

Results of our first study suggested that spirituality was a significant predictor of EI while Internal Religious Orientation was not. This finding is consistent with the past studies, such as the ones by Lee Flores et al. [54] and Miguel-Rojas et al [55]. One of the possible explanations for this result of the current study is that spirituality had found to be positively correlated with empathy, which is one of the main characteristics of EI [49, 38, 51, 10]. Furthermore, past research also suggested that spiritual practices (e.g. meditating or praying) could also help one in generating meaning and hope as well as getting consolation in different encounters, which subsequently promote positive emotions $[48,21]$. The positive emotions were probably linked to facets of trait EI like optimism and stress management, which eventually increase the overall EI [8]. Given that EI components include emotion regulation and emotion awareness, spirituality, which includes understanding of the connectedness between oneself, the environment and to a Divine Being, could also 
increase EI as it helps one to realize and understand one's own emotions and, in turn, helping one in regulating his or her emotions [55].

On the other hand, it was found that IRO did not significantly predict EI when spirituality was controlled. This is inconsistent with the past studies which found that IRO does significantly predicts EI. With that, few factors could be considered in explaining the results. First of all, most past research studied how IRO alone influence EI without taking into consideration of spirituality. Dooley et al. [56], suggested that although there might be a clear distinction between the definition of religiosity and spirituality by the scholar, most participants did not measure their religiosity based on ceremonial attendance or the degree to which they fit into their religious affiliation. Furthermore, past research showed that although there are arguments that spirituality is different from religion, the distinction is still not very well-defined [57]. Adding to that, some variables of religiosity and spirituality were found to be correlated, while some of them were not [36]. It was suggested that people with higher IRO tend to have higher spiritual maturity which helps them in perceiving and understanding emotions [43]. Thus, as they were participating in studies which investigate IRO as the only predictor of EI (where spirituality was not controlled for), they might take spirituality into consideration unconsciously since the terms religiosity and spirituality are often used interchangeably [56].

Besides that, participating in religious rituals or practices, like prayer and worshipping, would sometimes act as a means for people to develop their spirituality; that is to say, even though one could have been religious for the sake of social, financial, or other needs, it could also probably be one's way of expressing spirituality especially for individuals with higher IRO [36]. Accordingly, individuals with higher IRO often crave to understand faith; this craving, then, serve as a great motivator for them to develop a strong connection with a Divine Being who would guide them and provide them with meaning in life [56]. On top of that, people with higher IRO showed increase of engagement in their instiutions which sometimes involve spiritual teachings and helping the society in need [43]. By involving themselves such activities, it is possible that spiritual value like being compassionate and empathetic could be cultivated which eventually help them in improving EI [43, 60]. Furthermore, not only that the past research had found a significant positive correlation between IRO and spirituality, the current study and past studies also showed that IRO significantly predicted spirituality [61]. Therefore, past research which shows IRO significantly predicted EI may be due to spirituality as the underlying mechanism; hence, when spirituality was controlled in the study, IRO did not significantly predict EI.

\section{CONCLUSION}

The results of our second study indicated that spirituality explains the positive link between IRO and EI. In other words, without spirituality, IRO does not significantly predict EI. This finding might bridge the gap between the previous studies about religiosity (IRO) and spirituality without having to neglect the difference between the two factors.

It can be concluded that when religiosity and spirituality are taken as totally different factor, people can be categorized as religious but not spiritual, spiritual but not religious, religious and spiritual, or not spiritual and not religious. Our second study indicated that spiritual individuals, regardless they are religious or not, would likely to be emotionally intelligent. At the same time, non-spiritual individuals, despite they are highly religious, tend to be less likely emotionally intelligent.

Result of both study one and study two suggested that in order to improve EI, the emphasize of spiritual development holds more meaning than focusing solely on understanding religion as well as engaging in religious practices and rituals. As EI was found to be an important factor contributing to success in life, and the increase of job and academic performance, schools and organization could provide courses on spiritual development or implement spiritual practices without having any emphasize on certain belief system. Furthermore, organizations and educational institutions could prioritize on encouraging the practices of spiritual values such as being compassionate, respectful, humble, grateful, and honest to cultivate positive working environment and endorse teamwork within the institution as it may improve the students' EI instead of emphasizing in religious ceremonial knowledges. This would then reduce the internal conflict among students, educational stakeholders, and the society in general, as people with higher EI tends to be more prosocial, have higher self-esteem, and have better work attitudes.

Nevertheless, the second study also indicated that spirituality is significantly predicted by IRO. This means that religious institutions can also play their roles in improving the EI of their members by emphasizing on IRO instead of the extrinsic religious orientation (ERO). Leaders of religious affiliation should also provide guidance and examples that they do not use religion as a way to obtain their personal interest, social support, or political objectives; instead, they should give examples of embracing the spiritual values and focus their teaching to encourage their followers to seek for further sense of spirituality. 
Several limitations in the current study can be addressed to be taken into consideration. First of all, in order to avoid biases, we decided not to mention the religious affiliation of our participants. Despite reducing bias, this policy might decrease the meaningfulness of the findings due to the different nature of each belief system and the perception of the society towards each belief system. Second, most of the participants belong to one religious belief, and the rest of them were distributed to other religious beliefs and atheism. With that in mind, consideration might be put into conducting future research for certain religious belief system in order to obtain deeper understanding.

Another limitation of this study lies within its statistical results. Despite it can be considered strong $(\beta=.28)$, the total effect of IRO and spirituality can only explain $11 \%$ of the variance of the improvement of EI. This result suggested that there are larger percentage of variance that can be explained by other variables, which worth studying in the future. Furthermore, IRO can only explain $28 \%$ of the variance of $t$ he improvement in spirituality; which means that religiosity is not the only factor that can increase the spirituality among individuals. This finding also suggested that people can be highly religious without being spiritual or people with high spirituality are not always devoted to any organized religious instiution. This statistical finding might lead to further sociological or social-psychological question whether one requires to know any religious teaching in order to be spiritual and develop higher EI, which is suggested to be studied in future research.

Additionally, this study required participants to answer a few questionnaires where the first one contains 9 items, the second contains 28 items and the third one contains 33 items, participants may experience fatigue as the duration of the completion was relatively long. Moreover, it is also important to note that this was a self-reported study; people were usually more willing to identify themselves as spiritual rather than religious as being spiritual was seen to be positive and cool while religion was negatively connoted as people usually held a more skeptical view on religion. As a result, it is also possible that social desirability may influence the result as participants would tend to identify themselves as spiritual rather than religious. Hence, future research could use different means in measuring the components, such as including qualitative approach, to acquire a deeper understanding on participants' views on spirituality and religiosity. Additionally, future research could also explore deeper into the relationship by measuring participants' ability EI through testing their maximum performance as compared to measuring EI based on their subjective ratings on given statements.

\section{ACKNOWLEDGEMENTS}

This study has been funded by Internal Research Grant Scheme from ELM Graduate School, HELP University, Kuala Lumpur, in collaboration with Center of Cyberpsychology and Games, Psychology Dept. HELP University, Kuala Lumpur.

\section{REFERENCES}

[1] D. Goleman, "Emotional intelligence: Issues in paradigm building," The emotionally intelligent workplace, vol. 13, pp. 26, 2001

[2] V. Mattingly and K. Kraiger, "Can emotional intelligence be trained? A meta-analytical investigation," Human Resource Management Review, vol. 29, no. 2, pp. 140-155, 2019.

[3] R. Tajabadi, "The study of relationship between religious orientations with emotional intelligence components Among Students of Shahid Beheshti University of Medical Sciences," Archives of Advanced in Bioscience, vol. 8, no. 4, pp. 44-52, 2017.

[4] D. Nelis, J. Quoidbach, M. Mikolajczak, and M. Hansenne, "Increasing emotional intelligence: (How) is it possible?," Personality and individual differences, vol. 47, no. 1, pp. 36-41, 2009.

[5] J. D. Mayer, P. Salovey, D. R. Caruso, and G. Sitarenios, "Emotional intelligence as a standard intelligence," pp. 232, 2001.

[6] R. E. Boyatzis, D. Goleman, and K. Rhee, "Clustering competence in emotional intelligence: Insights from the Emotional Competence Inventory (ECI). Handbook of emotional intelligence," vol. 99, no. 6, pp. 343-362, 2000.

[7] M. Fiori, J. P. Antonietti, M. Mikolajczak, O. Luminet, M. Hansenne, and J. Rossier, "What is the ability emotional intelligence test (MSCEIT) good for? An evaluation using item response theory," PLoS One, vol. 9, no. 6, pp. e98827, 2014.

[8] K. V. Petrides, R. Pita, and F. Kokkinaki, "The location of trait emotional intelligence in personality factor space," British Journal of Psychology, vol. 98, no. 2, pp. 273-289, 2007.

[9] K. V. Petrides and A. Furnham, "Trait emotional intelligence: Behavioural validation in two studies of emotion recognition and reactivity to mood induction," European journal of personality, vol. 17, no. 1, pp. 39-57, 2003.

[10] O. Serrat, "Building a learning organization," in Knowledge solutions, Springer, pp. 57-67, Singapore, 2017.

[11] M. Mohamad and J. Jais, "Emotional intelligence and job performance: A study among Malaysian teachers," Procedia Economics and Finance, vol. 35, pp. 674-682, 2016. 
[12] L. B. Yoke and S. A. Panatik, "Emotional intelligence and job performance," International Business Management, vol. 10, no. 6, pp. 806-812, 2016.

[13] P. Ranasinghe, W. S. Wathurapatha, Y. Mathangasinghe, and G. Ponnamperuma, "Emotional intelligence, perceived stress and academic performance of Sri Lankan medical undergraduates," BMC medical education, vol. 17, no. 1, pp. 41, 2017.

[14] S. Swanepoel and L. Britz, "Emotional Intelligence and Academic Performance," Alternation Journal, vol. 20, pp. 171-188, 2017.

[15] B. Palmer, M. Walls, Z. Burgess, and C. Stough, "Emotional intelligence and effective leadership," Leadership \& Organization Development Journal, vol. 22, no. 1, pp. 5-10, 2001.

[16] P. N. Lopes, M. A. Brackett, J. B. Nezlek, A. Schütz, I. Sellin, and P. Salovey, "Emotional intelligence and social interaction," Personality and social psychology bulletin, vol. 30, no. 8, pp. 1018-1034, 2004.

[17] A. Drigas and C. Papoutsi, "Emotional Intelligence as an Important Asset for HR in Organizations: Leaders and Employees," International Journal of Advanced Corporate Learning, vol. 12, no. 1, 2019.

[18] N. Extremera and P. Fernández-Berrocal, "Perceived emotional intelligence and life satisfaction: Predictive and incremental validity using the Trait Meta-Mood Scale," Personality and Individual Differences, vol. 39, no. 5, pp. 937-948, 2005.

[19] L. Rey, N. Extremera, and M. Pena, "Perceived emotional intelligence, self-esteem and life satisfaction in adolescents," Psychosocial Intervention, vol. 20, no. 2, pp. 227-234, 2011.

[20] S. K. Davis and N. Humphrey, "The influence of emotional intelligence (EI) on coping and mental health in adolescence: Divergent roles for trait and ability EI," Journal of Adolescence, vol. 35, no. 5, pp. 1369-1379, 2012.

[21] C. L. Park and J. M. Slattery, "Spirituality, emotions, and physical health," in The Oxford handbook of psychology and spirituality, pp. 379-387, 2012.

[22] A. Vishkin, Y. E. Bigman, R. Porat, N. Solak, E. Halperin, and M. Tamir, "God rest our hearts: Religiosity and cognitive reappraisal," Emotion, vol. 16, no. 2, pp. 252, 2016.

[23] I. D. Gaur, "Issues of canons and cultures," Cultural Studies in India, pp. 139, 2017.

[24] B. W. Smith, J. A. Ortiz, K. T. Wiggins, J. F. Bernard, and J. Dalen, "Spirituality, resilience, and positive emotions," in The Oxford handbook of psychology and spirituality, Oxford library of psychology, pp. 437-454, Oxford, 2012.

[25] P. Van Cappellen, M. Toth-Gauthier, V. Saroglou, and B. L. Fredrickson, "Religion and well-being: The mediating role of positive emotions," Journal of Happiness Studies, vol. 17, no. 2, pp. 485-505, 2016.

[26] I. Silberman, "COMMENTARY:"Spiritual Role Modeling: The Teaching of Meaning Systems," The international Journal for the Psychology of Religion, vol. 13, no. 3, pp. 175-195, 2003.

[27] C. L. Park, "Religiousness/spirituality and health: A meaning systems perspectives," Journal of Behavioural Medicine, vol. 30, no. 4, pp. 319-328, 2007.

[28] C. G. Ellison, "Religious Involvement and Subjective Well-Being," Journal of Health and Social Behavior, vol. 32, no. 1, pp. 80-99, 1991.

[29] R. W. H. P. C. Hood Jr and B. Spilka, The psychology of religion: An empirical approach, New York: Guilford, 2009.

[30] A. Vishkin, P. B. N. Bloom, and M. Tamir, "Always look on the bright side of life: Religiosity, emotion regulation and well-being in a Jewish and Christian sample," Journal of Happiness Studies, vol. 20, no. 2, pp. 427-447, 2019.

[31] B. J. Zinnbauer, K. I. Pargament, B. Cole, M. S. Rye, E. M. Butter, T. G. Belavich, K. M. Hipp, A. B. Scott and J. L. Kadar, "Religion and spirituality: Unfuzzying the fuzzy," Journal for the Scientific Study of Religion, pp. 549-564, 1997.

[32] B. J. Zinnbauer and K. I. Pargament, "Religiousness and spirituality," in Handbook of the psychology of religion and spirituality, New York, The Guilford Press, pp. 21-42, 2005.

[33] J. W. Howden, Development and psychometric characteristics of the Spirituality Assessment Scale, Texas Woman's University, Denton, 1992.

[34] K. L. Walker and V. Dixon, "Spirituality and academic performance among African American college students," Journal of Black Psychology, vol. 28, no. 2, pp. 107-121, 2002.

[35] H. Koenig, H. G. Koenig, D. King, and V. B. Carson, Handbook of religion and health, New York: Oxford University Press, 2012.

[36] L. A. Berkel, T. D. Armstrong, and K. O. Cokley, "Similarities and differences between religiosity and spirituality in African American college students: A preliminary investigation," Counseling and Values, vol. 49, no. 1, pp. 2-14, 2004.

[37] A. Bovero, P. Leombruni, M. Miniotti, G. Rocca, and R. Torta, "Spirituality, quality of life, psychological adjustment in terminal cancer patients in hospice," European Journal of Cancer Care, vol. 25, no. 6, pp. 961-969, 2015.

[38] M. de Souza, "The empathetic mind: the essence of human spirituality," International Journal of Children's Spirituality, vol. 19, no. 1, pp. 45-54, 2014.

[39] G. W. Allport and J. M. Ross, "Personal religious orientation and prejudice," Journal of Personality and Social Psychology, vol. 5, no. 4, pp. 432-443, 1967.

[40] M. Ardelt and C. S. Koenig, "The importance of religious orientation and purpose in life for dying well: Evidence from three case studies," Journal of Religion, Spirituality \& Aging, vol. 19, no. 4, pp. 61-79, 2007.

[41] C. J. Van Dyke and M. J. Elias, "How expressions of forgiveness, purpose, and religiosity relate to emotional intelligence and self-concept in urban fifth-grade students," American Journal of Orthopsychiatry, vol. 78, no. 4, pp. 481-493, 2008.

Why some religious individuals are not emotionally smart? The explanatory role of spirituality (Hui Wen $\mathrm{Ng})$ 
[42] P. Łowicki and M. Zajenkowski, "Divine emotions: On the link between emotional intelligence and religious belief," Journal of Religion and Health, vol. 56, no. 6, pp. 1998-2009, 2017.

[43] E. Paek, "Religiosity and perceived emotional intelligence among Christians," Personality and Individual Differences, vol. 41, no. 3, pp. 479-490, 2006.

[44] L. M. Prati, Y. Liu, and K. Bass, "Religiosity and workplace behaviour: a manifestation of emotional intelligence," Journal of Management, Spirituality \& Religion, vol. 4, no. 2, pp. 138-159, 2007.

[45] R. L. Bassett and P. C. Hill, "The ACE model of emotion: living Jesus Christ while experiencing emotions," Journal of Psychology and Theology, vol. 26, no. 3, pp. 232-246, 1998.

[46] A. B. Cohen and P. C. Hill, "Religion as culture: Religious individualism and collectivism among American Catholics, Jews, and Protestants," Journal of Personality, vol. 75, no. 4, pp. 709-742, 2007.

[47] K. Geula, Emotional intelligence and spiritual development, Santa Cruz, California, 2004.

[48] J. Coyle, "Spirituality and health: Towards a framework for exploring the relationship between spirituality and health," Journal of Advanced Nursing, vol. 37, no. 6, pp. 589-597, 2002.

[49] A. Apostolides, "Empathy and imagination: Nurturing children's and adolescent's spiritual well-being in the digital environment," Stellenbosch Theological Journal, vol. 4, no. 1, pp. 73-89, 2018.

[50] Y. Y. Tang, B. K. Hölzel, and M. I. Posner, "The neuroscience of mindfulness meditation," Nature Reviews Neuroscience, vol. 16, no. 4, pp. 213-225, 2015.

[51] A. Lutz, J. Brefczynski-Lewis, T. Johnstone, and R. J. Davidson, "Regulation of the neural circuitry of emotion by compassion meditation: effects of meditative expertise," PloS one, vol. 3, no. 3, pp. e1897, 2008.

[52] C. A. Markstrom, E. Huey, B. M. Stiles, and A. L. Krause, "Frameworks of caring and helping in adolescence: Are empathy, religiosity, and spirituality related constructs?," Youth \& Society, vol. 42, no. 1, pp. 59-80, 2010.

[53] P. Salovey and J. D. Mayer, "Emotional intelligence," Imagination, Cognition and Personality, vol. 9, no. 3, pp. 185-211, 1990.

[54] S. Lee Flores, M. T. Green, P. A. Duncan, and M. A. Carmody-Bubb, "The relationship between spirituality and emotional intelligence," International Journal of Religion \& Spirituality in Society, vol. 3, no. 2, pp. 93-105, 2013.

[55] J. Miguel-Rojas, E. Vílchez-Quevedo, and M. Reyes-Bossio, "Spirituality and Emotional Intelligence in university students of the city of Ayacucho," Interacciones: Revista de Avances En Psicología, vol. 4, no. 2, pp. 131-141, 2018.

[56] M. Dooley, D. Jones, and E. Zupko, "Dissecting faith: Comparing religiousness and spirituality to self-construal and religious orientation," Psi Chi Journal of Undergraduate Research, vol. 15, no. 4, pp. 186-193, 2010.

[57] B. Steensland, X. Wang and L. C. Schmidt, "Spirituality: What Does it Mean and to Whom?," Journal for the Scientific Study of Religion, vol. 57, no. 3, pp. 450-472, 2018.

[58] J. Brewczynski and D. A. MacDonald, "Confirmatory factor analysis of the allport and ross religious orientation scale with a polish sample," The International Journal for the Psychology of Religion, vol. 16, no. 1, pp. 63-76, 2006.

[59] N. S. Schutte, J. M. Malouff, L. E. Hall, D. J. Haggerty, J. T. Cooper, C. J. Golden, and L. Dornheim, "Development and validation of a measure of emotional intelligence," Personality and Individual Differences, vol. 25 , no. 2, pp. 167-177, 1998.

[60] L. Reave, "Spiritual values and practices related to leadership effectiveness," The Leadership Quarterly, vol. 16, no. 5, pp. 655-687, 2005 .

[61] M. L. Campbell, S. A. Lee, and D. L. Cothran, "Mysticism matters: Distinguishing between intrinsic religiosity, extrinsic religiosity, and spirituality using higher-order factors of personality and mysticism," Archive for the Psychology of Religion, vol. 32, no. 2, pp. 195-216, 2010. 